\title{
Tracheopathia osteoplastica
}

\author{
S. P. B. WA $Y^{1}$ \\ From the Department of Pathology, St Mary's Hospital Medical School, London
}

SYNOPSIS Only four cases of tracheopathia osteoplastica have been reported in Britain in the past 110 years. Ten further cases are now reported; in two the diagnosis was made at bronchoscopy. It is suggested that the reputed rarity of the condition in Britain is not the whole picture.

Tracheopathia osteoplastica is a condition in which there is an accumulation of bony and cartilaginous nodules beneath the tracheal mucosa, sometimes spreading into the main bronchi, and occasionally affecting the larynx. More than 120 cases have been described in the world literature, including some distinguished accounts of the disease, but in Britain only three cases (Bowen, 1959; Salm, 1961; Baird and Macartney, 1966) have been reported since 1857 when Samuel Wilks, physician and morbid anatomist to Guy's Hospital, first described ossific deposits on the larynx, trachea, and bronchi in a man aged 38 who died of phthisis. Ten further cases can now be reported.

In 1952, a woman aged 61, who had collapsed and died at work, was brought to St Mary's Hospital, where the cause of death was found to be coronary occlusion; tracheopathia osteoplastica was present and the specimen was preserved (case 1, Fig. 1). Ten years later, a man aged 51 died after a coronary thrombosis and again, at necropsy, tracheopathia osteoplastica was found in the trachea (case 2, Fig. 2). Soon afterwards, the diagnosis was made at bronchoscopy when a small osteoma was removed in a case of carcinoma of the lung (case 10). Discussion with various pathologists then brought to light seven further cases.

\section{CASE REPORTS}

CASE 1 A woman aged 61 collapsed and died at work. The cause of death was right coronary artery occlusion by haemorrhage into an atheromatous plaque. The lower $7 \mathrm{~cm}$. of the trachea had a longitudinally wrinkled appearance due to the presence of many hard nodules and plaques, often confluent (Fig. 1). The nodules were present only on the cartilaginous part of the tracheal

1 Present address: Pathology Laboratory, The Guest Hospital, Dudley, Worcestershire.

Received for publication 6 April 1967.

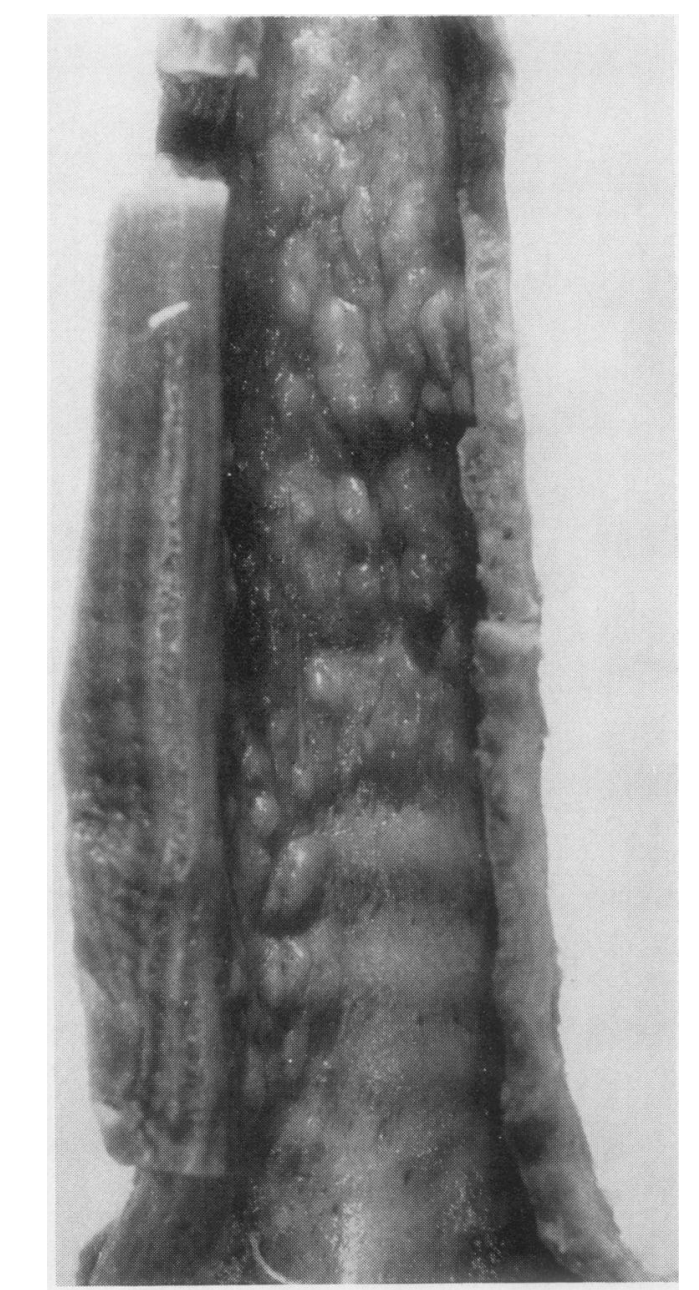

FIG. 1. Case 1. Trachea, showing the confluent nodules and plaques and the longitudinal wrinkling of the trachea. The nodules are confined to the anterior portion. 


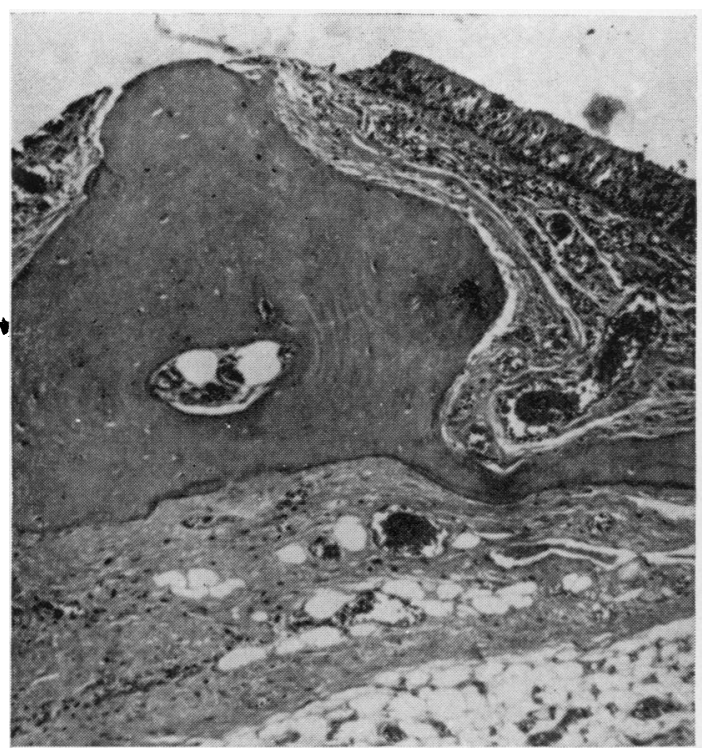

FIG. 2. Case 1. A nodule of bone lying on its own in the submucosa, unconnected with neighbouring bone or with the tracheal cartilage. Haematoxylin and eosin. $\times 100$.

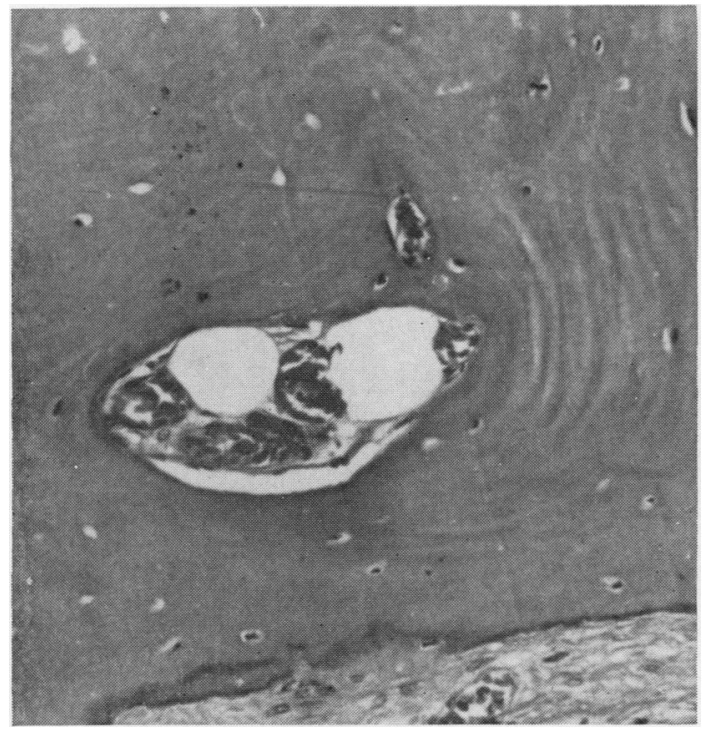

FIG. 3. Case 1. High-power view of the section seen in Figure 2. A central canal in the bone containing blood vessels and a small quantity of fatty marrow. Haemato$x y l i n$ and eosin. $\times 256$. circumference and the affected portion of the trachea was stiffer than the rest.

Histology Nodules and plaques were seen lying in the lamina propria (Fig. 2). Most were cartilaginous and some showed ossification. Continuity with the normal cartilaginous rings was sometimes noted, and the tracheal rings did not show ossification. A striking feature was the presence of fatty marrow in some cyst-like bony deposits

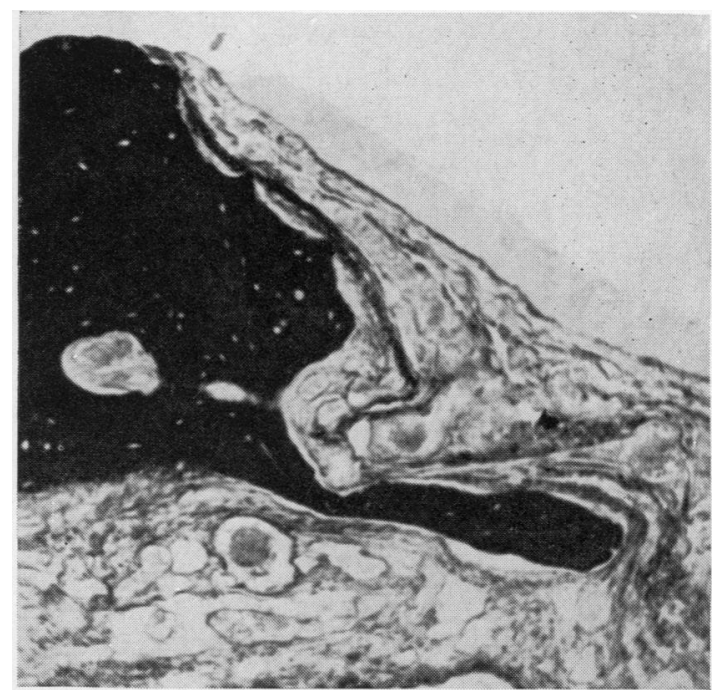

FIG. 4. Case 1. The same nodule as in Figure 3 stained for elastic (Hart-Sheridan and van Gieson) to demonstrate the close investment of the periosteum of the nodule by elastic fibres. $\times 100$.

(Fig. 3). The submucous elastica had a close relationship to the bony and cartilaginous nodules, and elastic fibres swept round and invested their periosteum closely (Fig. 4).

CASE 2 A man aged 51 was brought in dead and necropsy showed the cause of death to be coronary thrombosis and cardiac infarction, with linear ruptures of the haemorrhagic myocardium. The first oblique branch of the right coronary artery was thrombosed at the site of some calcification. The lower portion of the trachea had an inflamed and congested mucous membrane and about $4-5 \mathrm{~cm}$. from the bifurcation the membrane was nodular and rugose (Fig. 5). The nodules stood out white in colour, some confluent, and none more than 3 $\mathrm{mm}$. in diameter except where they were close together. They were present over the interspaces as well as in the cartilaginous rings.

Histology The nodules of bone lay immediately beneath the basement membrane of the columnar cell mucous membrane of the trachea, which was largely intact. Mucous glands often separated the nodules from the tracheal rings (Fig. 6), but the nodules sometimes formed the superficial part, or cap, of an ecchondrosis or 


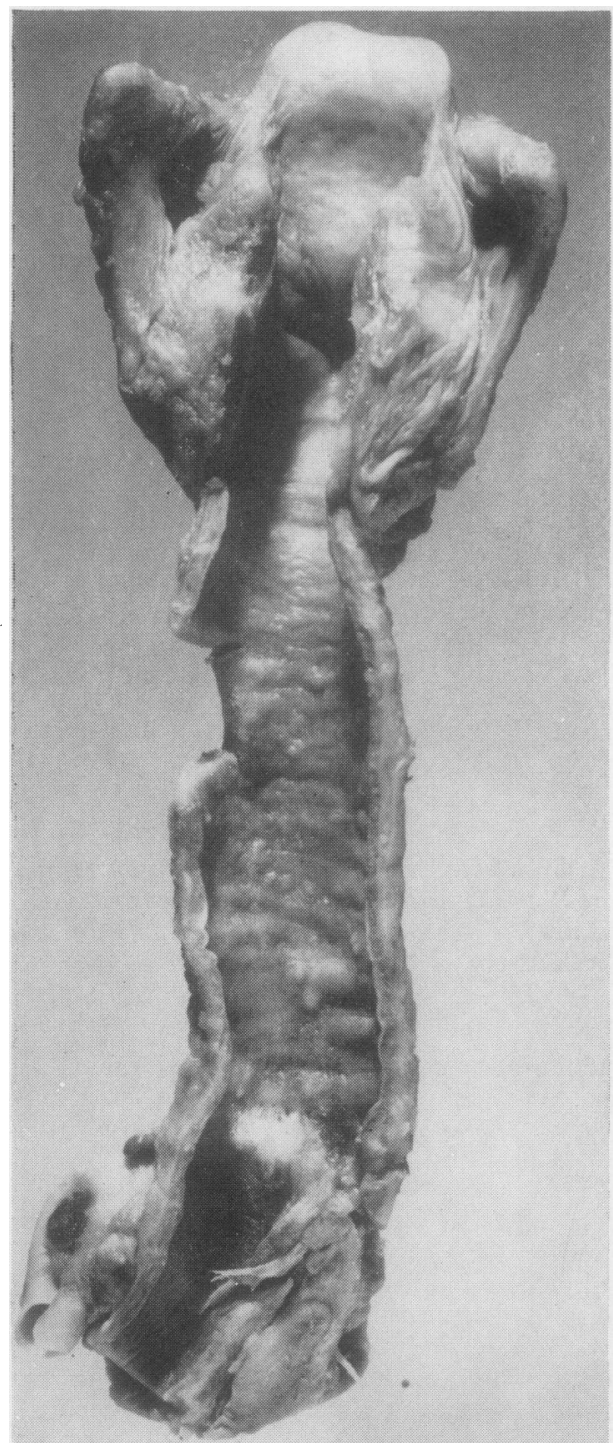

FIG. 5. Case 2. Trachea, showing the inflamed and congested mucous membrane and the nodular and rugose mucosa. The nodules were not more than $3 \mathrm{~mm}$. diameter except where they were close together.

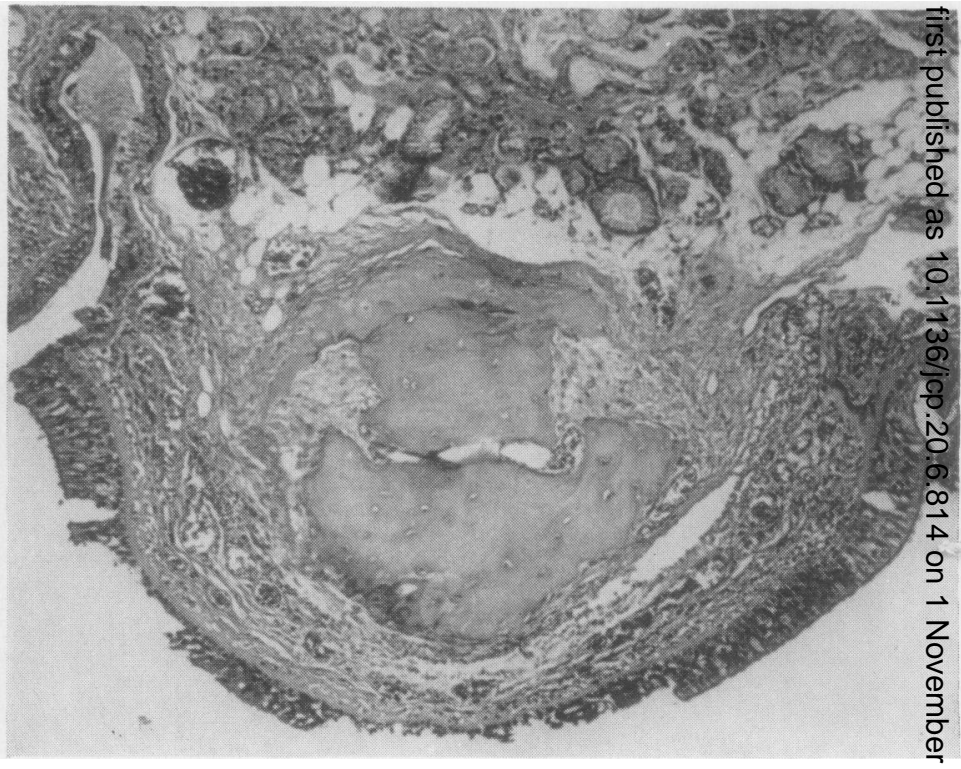

FIG. 6. Case 2. Another highly characteristic isolated nodule of bone with $\mathrm{a}$ little attached cartilage at its base. Submucous glands lie between it and Ife tracheal ring. Haematoxylin and eosin. $\times 100$.

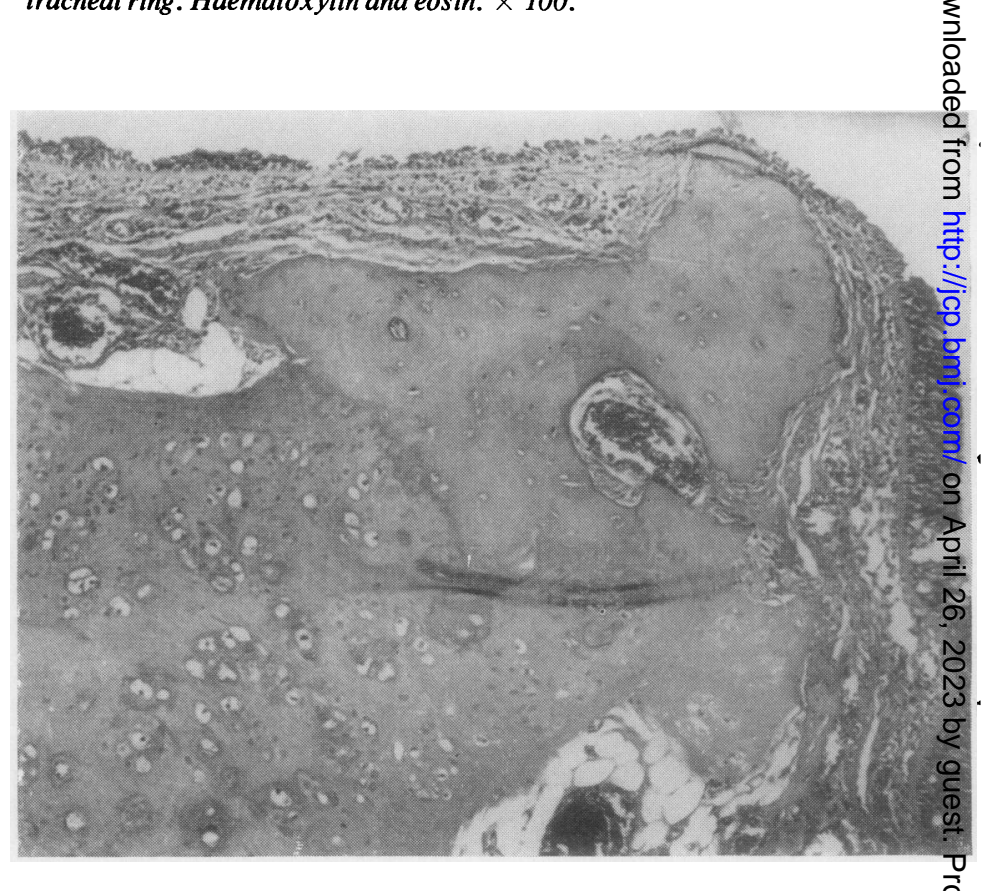

FIG. 7. Case 2. A bony nodule on a long cartilaginous projection (an ecch drosis) from the tracheal ring beneath. The mucosa is partly denuded over it $\frac{\vec{d}}{\mathrm{~d}} a$ frequent finding - and there is a small marrow space. Haematoxylin and eosin. $\times 100$. 
projection of the cartilage from the tracheal ring (Fig. 7). Marrow spaces were present in some of the more solid bony nodules, in which Haversian systems were seen.

CASE 3 A man aged 62 was admitted to hospital with a four-hour history of breathlessness. He had had a similar episode a year previously. Blood pressure was $200 / 130 \mathrm{~mm}$. $\mathrm{Hg}$; an electrocardiogram suggested coronary thrombosis; serum transaminase was within normal limits; chest radiographs confirmed the presence of pulmonary oedema. He was treated for cardiac failure and anticoagulant therapy was started but he died a week later. At necropsy there was evidence of recent and old cardiac infarction involving three-fifths of the left ventricle, with myocardial hypertrophy (heart weight $450 \mathrm{~g}$.). The right coronary artery was occluded by atheromatous paste and thrombus and severe atheroma was present throughout both coronary arteries. The true laryngeal cords, trachea, and both bronchi were red with white irregular raised plaques and 'trabeculae'. The lungs were normal apart from an emphysematous bulla.

Histology The appearances were similar to those in cases 1 and 2, with submucosal nodularities consisting of cartilaginous outgrowths from the tracheal rings undergoing calcification and ossification. One bony spicule contained a marrow space. A feature of interest was the presence of a granular substance, almost colourless, scattered in the islets of ossifying cartilage. The tracheal ring was also involved by this substance which appeared as hyaline granules, often of some size (up to 30-40 $\mu$ ), with no significant colour. The granular substance gave a Prussian blue reaction (Perls' method) (Fig. 8). This association of iron pigments with ossification appears to be unique and was not demonstrable in the other cases of tracheopathia osteoplastica that it was possible to test, either by the demonstration of a granular pigment

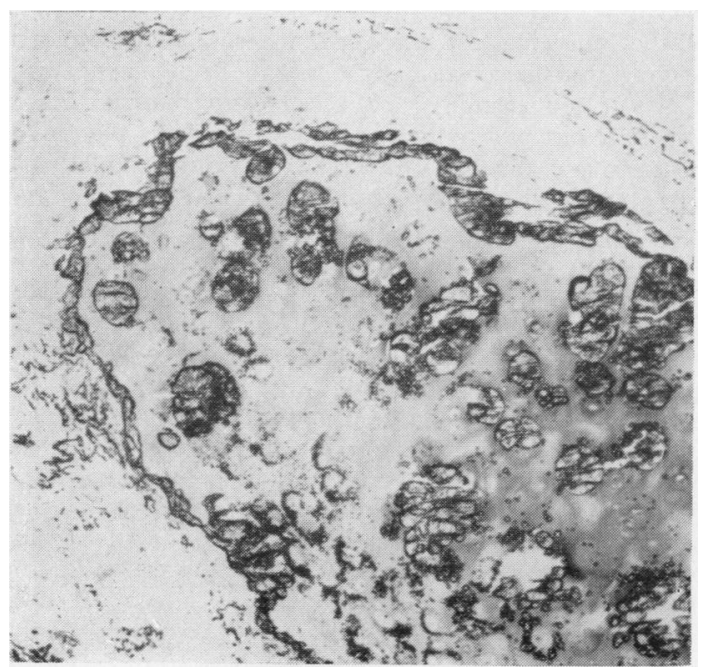

FIG. 8. Case 3. An island of cartilage showing the presence of iron granules giving a strongly positive Prussian blue reaction. Perls' method. $\times 100$. visually, or by the Prussian blue reaction. The most probable explanation is that it represents old haemorrhage into the tracheal mucosa, but how haemorrhage reaches the central portion of the tracheal cartilage rings is not clear as they are avascular unless they have been fractured at some time. There was no history of haemoptysis in this case.

CASE 4 A man aged 57 was found at necropsy to have marked myocardial fibrosis, and the trachea was noted as being nodular. Details of the patient's history are not available.

Histology The tracheal mucosa was replaced by stratified squamous epithelium, and beneath this several bony spicules were present (Fig. 9). No ecchondroses were noted. Several marrow spaces were seen and one

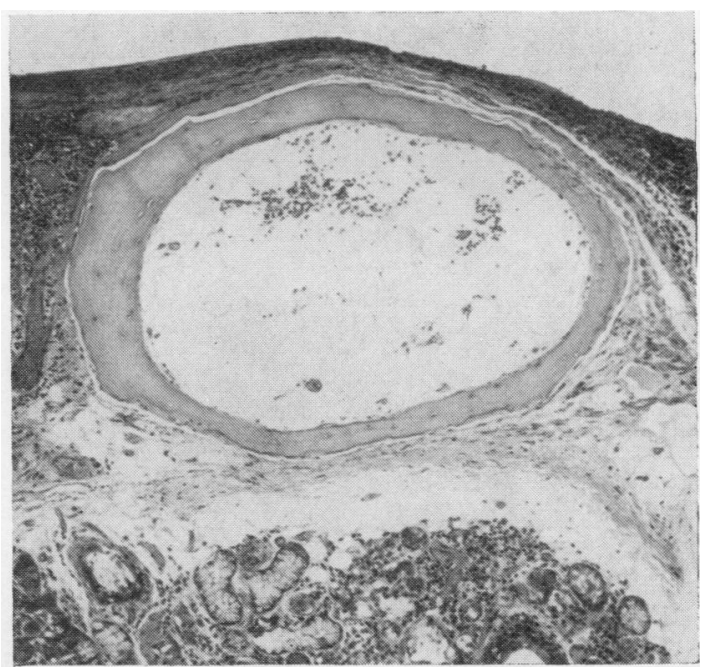

FIG. 9. Case 4. An unattached bony cyst containing marrow, some of it possibly haemopoietic. The overlying mucosa has undergone squamous metaplasia. Haematoxylin and eosin. $\times 100$.

appeared to show haemopoiesis. Elastic fibres sweeping round the bony nodules were conspicuous.

CASE 5 A woman aged 79 died of gastric ulcer and haematemesis. Details of her history are not available, but at necropsy the appearance of the trachea was noted as being abnormal.

Histology Longitudinal sections of the trachea showed multiple nodules of bone and cartilage beneath the mucosa, which was absent, only the basement membrane being represented. Some of the bony nodules contained marrow spaces filled with fat cells. There was a close relationship between the elastic tissue and the perichondrium. Some of the largest nodules consisted of cartilage only. 


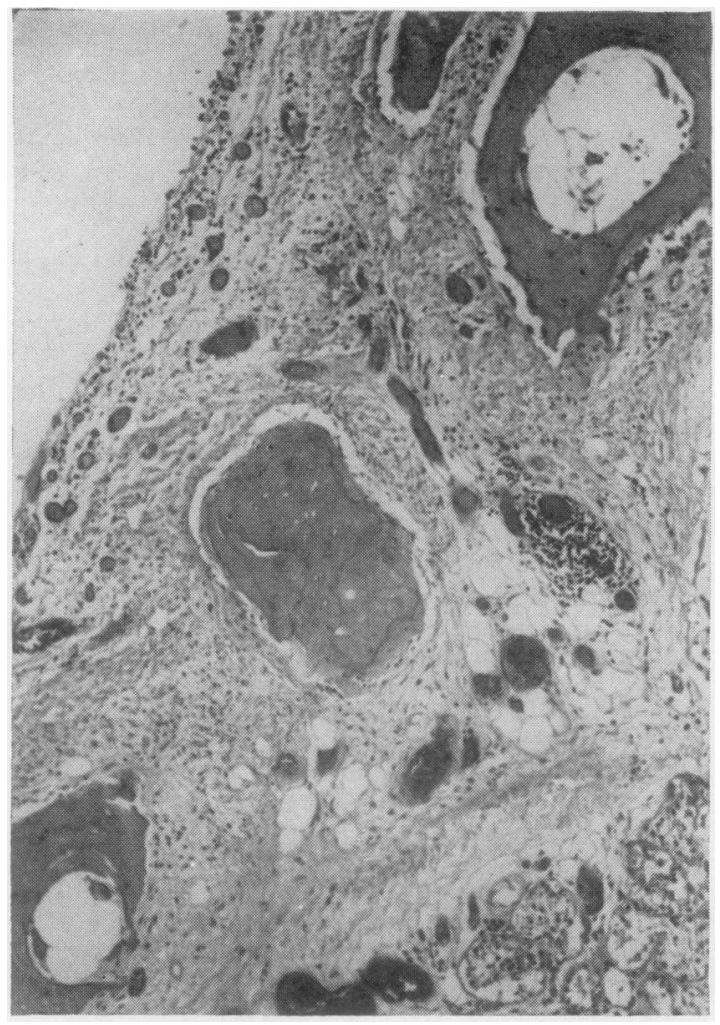

FIG. 10. Case 6. This section shows the general relationship the bony nodules have to one another in the submucosa. Two of the nodules have marrow spaces, with fatty marrow therein. Haematoxylin and eosin. $\times 100$.

CASE 6 This 58-year-old gardener suffered severe chest pain during the night and on the following morning he was found dead at his work. Necropsy disclosed a coronary thrombosis with myocardial infarction. There was old chronic fibrous tuberculosis in the lungs. The larger bronchi and trachea had a yellowish and purple-red granular hard surface.

Histology The trachea contained irregular plaques of lamellar bone formation in the mucosa, several showing fatty marrow in their medullary cavities (Fig. 10). Obvious haemopoiesis was not identified. The largest bony plaque measured $2-3 \mathrm{~mm}$. across and was $1.5 \mathrm{~mm}$. thick, being sessile on the calcified cartilaginous tracheal ring which was about $2.5 \mathrm{~mm}$. at the thickest point. Between the bony nodules and the tracheal cartilage a clear band of fibrous perichondrium (and periosteum) was seen. There was a break in the band of elastic fibres around the periosteum at this point. Fourteen nodules of bone or cartilage were seen in a hemisection of the trachea. One small bony nodule was traced, arising directly from the cartilage of the tracheal ring without the presence of fibrous perichondrium between it and the cartilage of the trachea. The tonsil contained a small piece of bone deep to the lymphoid tissue which showed chronic inflammatory change and fibrosis.

CASE 7 In this patient, a man of 59, tracheopathia osteoplastica was diagnosed during life. Hitherto a fit man, he began to feel tired and developed slight cough and fever, with right thoracic pain. After a radiograph of the chest he was admitted to hospital and underwent bronchoscopy, at which tracheopathia osteoplastica was diagnosed. He was found to have carcinoma of the lung and a right pneumonectomy was performed; Pancoast's syndrome was present. He made an uneventful recovery but suffered from attacks of dyspnoea, during one of which he died. At necropsy the pin-sized white points were seen projecting into the 'front and back' (sic) of the trachea and larynx.

Histology Microscopical examination proved the presence of the characteristic bony and cartilaginous nodules; many were attached to the tracheal rings.

CASE 8 This man aged 59 had recurrent attacks of haematuria for two years. The prostate was enlarged; blood pressure was $160 / 110 \mathrm{~mm}$. Hg and blood urea was $86 \mathrm{mg} . / 100 \mathrm{ml}$. The right kidney was thought to be abnormal and cystotomy was performed for urinary retention. He was subsequently readmitted with a recurrence of haematuria; stilboestrol was given, but a rising blood urea was followed by neurological symptoms and a large space-occupying lesion in the brain was suspected. Necropsy showed polycystic renal disease, cystic liver, prostatic hyperplasia, and a cerebral infarction of the left hemisphere. A mild degree of tracheopathia osteoplastica was found in the trachea.

Histology Eleven bony and cartilaginous nodules were present in one hemisection of the trachea, mostly lying midway between the mucosa and the tracheal cartilage. The larger pieces of bone measured $0.85 \times$ $0.45 \mathrm{~mm}$., the smallest not more than $0.135 \mathrm{~mm}$. Some of the bony plaques contained marrow spaces, and in one of these there was a slight excess of polymorphs with a few more primitive cells suggesting haemopoiesis. Others contained only fatty marrow. One plaque of cartilage contained a little calcium, with no bone formation, but in a smaller piece of cartilage there was bone formation.

CASE 9 A man aged 82 suffered from gradual heart failure for nine months, following influenza. Despite mersalyl and digoxin he did poorly, dying two weeks after admission to hospital with recurrent and old infarctions and coronary atherosclerosis. At necropsy extensive nodules were present beneath the tracheal mucous membrane from the bifurcation to the larynx.

Histology Microscopical examination of the trachea proved entirely characteristic with cartilaginous and bony submucosal nodules, one of which was sessile on a tracheal ring.

CASE 10 This man of 64 underwent bronchoscopy for carcinoma of the lung. The tracheal appearance was thought to show the presence of tracheopathia osteoplastic and a nodule was removed. The left upper lobe 
was resected for squamous cell carcinoma of the bronchus.

Histology Microscopical examination of the nodule removed at bronchoscopy confirmed its bony nature.

\section{DISCUSSION}

These 10 cases have in common the presence of bony and cartilaginous nodules beneath the mucous membrane of the trachea. In several cases fatty bone marrow has been identified in the bony nodules when they appear like cysts, and in two cases erythropoietic marrow has been seen (cases 4 and 8). With regard to the distribution, the bony nodules have been seen in the tonsil (case 6) and apparently affecting the cords of the larynx (cases 3 and 7). In all except one (case 7) the membranous part of the trachea has been spared; in case 7 pin-sized white points were seen projecting from the 'front and back' (sic) of the trachea and larynx.

The bony nodules beneath the trachea were for the most part separated from the cartilaginous nodules, but the actual process of ossification of cartilage was found quite frequently (cases $2,3,4$, and 5).

Elastic tissue has been looked for in sections from all the cases (using Hart-Sheridan's method for elastic tissue, counterstained by van Gieson's method), and it has been found frequently in close association with the perichondrium, and more particularly with the bone in three cases (cases 1, 4, and 5 , in which there is a veritable profusion of elastic fibres round the bony and cartilaginous nodules). This tallies with Aschoff's (1910) theory that these bony and cartilaginous nodules arise by metaplasia, in association with the connective tissue cells which form the elastic fibres of the lamina propria of the trachea. However, Bowen (1959) was unable to confirm this finding and Salm (1961) states his belief that the elastic theory is significant only because the cartilaginous and osseous deposits lie side by side with elastic fibres in the lamina propria. He interprets Aschoff as meaning only that there was a connective tissue change in the same situation, not that there was an actual metaplasia of the elastic tissue.

A study of some of the sections from these 10 cases has shown the tiniest nodules of cartilage and bone between the tracheal rings. Other sections, in contrast, have revealed the presence of ecchondroses, so it is evident that both these processes occur, and the theory that the bony nodules sometimes arise from the ecchondroses cannot be taken to imply that they always do so. Neither are there sufficient ecchondroses to make it seem possible for the inter- cartilaginous deposits (those between the rings) to have arisen as fragments each from the edge of an ecchondrosis.

The cause of these bony and cartilaginous deposits is therefore open to speculation. The older authorsEppinger (1880), Dreyfuss (1910, 1916), Tanturri (1935), and Hart and Mayer (1928)-suggested a chronic inflammation such as syphilis or tuberculosis; they also suggested an association with chronic bronchitis, which would lead one to expect the condition as an everyday occurrence in British mortuaries, which it is not. Hitherto, in Britain only four cases have been reported. Nevertheless, the present report of 10 cases demonstrates that, if carefully enquired for among pathologists, examples are forthcoming without undue difficulty, and as the trachea is regularly examined in necropsies in this country, it may well be assumed that further caseslie unreported in many places. Of these 10 cases, seven come from the London area, two from Birmingham, and one from Cambridge. It is surprising that this phenomenon is not more frequently seen and described by bronchoscopists, as by personal enquiry the author finds it is not in fact often seen or always known. To see it once is to know it for all time, the appearances being so striking in the well developed case as two well-known atlases of bronchoscopy illustrate it (Jackson and Jackson, 1950; Huzley, 1960).

Hempel and Gläser (1958), who between them have given an account of eight cases, in speculations on its aetiology attributed it to acidosis arising from metabolic or local inflammatory disturbances, whereby a hyaline pre-cartilaginous swelling is produced in the connective tissue beneath the tracheal mucosa. No satisfactory way of confirming the presence of such an agency causing acidosis has come to light. Tobacco smoke could be a possible stimulus for an unusual defence reaction in the trachea, which is so open to the noxious effects of smoke and chemical vapours, and cigarette smoking has been proved to have an association with lung cancer (Doll and Hill, 1952); however, the incidence of lung cancer far exceeds the incidence of tracheopathia osteoplastica.

The presence of iron pigment in the cartilage in case 3 appears not to have been reported before and is not easily explained. Haemoptysis has been reported as a symptom (Jackson and Jackson, 1932; Clerf, 1944) and it is tempting to think of localized haemorrhage in the tracheal mucosa as an explanation for the presence of this iron pigment, but this patient had no history of haemoptysis or of trauma (such as might arise from bronchoscopic investigation).

Neoplasia was rejected as a possible theory by 
Ribbert (1904, quoted by Dalgaard, 1947) as tracheopathia osteoplastica lacks the feature of continued growth; the nodules appear to be self-limiting in size, and only rarely have chondromata been removed by the bronchoscope. In case 10 a tiny osteoma was removed at bronchoscopy, reminding one of Spencer's (1962) view that the condition should not be regarded as confined to the trachea; he terms it 'bronchopathia osteoplastica', implying that it is one with bronchopulmonary ossifications.

In the present series of eight men and two women, no less than six cases (cases 1, 2, 3, 4, 6 and 9) have been found in association with coronary artery disease, from thrombosis and haemorrhage to coronary artery atherosclerosis and myocardial fibrosis, but in view of the prevalence of sudden death attributable to coronary artery disease no association between the two conditions can be claimed. Cases 7 and 10 were associated with carcinoma of the lung, but this association was recorded for the first time in 1955 by Dalgaard.

Secrest, Kendig, and Beland (1964), in the United States, reported that five of 104 cases of tracheopathia osteoplastica had been recognized in life from routine chest radiographs and tomographs of the trachea, followed by bronchoscopy. The four previous cases reported in Britain were diagnosed after death. In eight of the present 10 cases, the disorder was an incidental finding at necropsy, and in two the diagnosis was made at bronchoscopy. This suggests that tracheopathia osteoplastica is seen more often than one would expect, though it may not always be reported or even diagnosed, and that the reputed rarity of the condition in Britain is not the whole picture.
My thanks are due to Professor D. M. Pryce, St. Mary's Hospital Medical School, who first drew my attention to $\stackrel{S}{\rightarrow}$ the condition, and to the following for kindly allowing 0 me to record their cases: Dr. S. Robinson and Dr. C. 흐 Bryson, formerly of Archway Central Histological $\frac{\bar{\sigma}}{2}$ Laboratory, Highgate; Dr. P. M. Peters, Royal Northern $\overparen{\mathbb{}}$ Hospital; Dr. R. A. Carter, formerly of the Department $\varrho$ of Pathology, Cambridge University; Dr. J. V. Garrett के and Dr. J. S. McKinnell, of Selly Oak Hospital, Birming- $\vec{\circ}$ ham; Professor J. V. Harrison, Dr. P. Hugh-Jones and Dr. B. Heard, Postgraduate Medical School of London; and Mr. L. Bromley, St. Mary's Hospital, London.

\section{REFERENCES}

Aschoff, L. (1910). Verh. dtsch. path. Ges., 125.

Baird, R. B., and Macartney, J. N. (1966). Thorax, 21, 321.

Bowen, D. A. L. (1959). J. clin. Path., 12, 435.

Clerf, L. H. (1944). Ann. oto.-rhino.-Laryng., 53, 839.

Dalgaard, J. B. (1947). Acta path. microbiol. scand., 24, 118.

- (1955). Nord. Med. 53, 572.

Doll R., and Hill, A. B. (1952). Brit. med. J., 2, 1271.

Dreyfuss, R. (1910). Arch. Laryng. Rhin. (Berl.)., 23, 318.

(1916). Bruns' Beitr. klin. Chir., 102, 426.

Eppinger, H. (1880). Pathologische Anatomie der Larynx und der Trachea Klebs' Handbuch der Pathologischen Anatomie, Bd. 2, Abth. 1, Lief 1, p. 299. A. Hirschwald, Berlin.

Hart, C., and Mayer, E. (1928). In Henke-Lubarsch: Handbuch der spezellen pathologischen Anatomie und Histologie, vol. 3, p. 305. Springer, Berlin.

Hempel, K. J., and Gläser, A. (1958). Virchows Arch. path. Anat., . $331,36$.

Huzley, A. (1960). An Atlas of Bronchoscopy, pp. 22, 58, Grune and Stratton, New York and London.

Jackson, C., and Jackson, C. L. (1932). J. Amer. med. Ass., 99, 1747. (1950). Bronchoesophagology, pp. 170, 186. Saunders, Philadelphia and London.

Ribbert, M. W. H. (1904). Geschwulstlehre, pp. 133-5 and 162. F. Cohen, Bonn. Quoted by Dalgaard (1947).

Salm, R. (1961). Thorax, 16, 382.

Secrest, P. G., Kendig, T.A., and Beland, A. J. (1964). Amer. J. Med., 36, 815.

Spencer, H. (1962). Pathology of the Lung, Excluding Pulmonary Tuberculosis. Pergamon Press, Oxford.

Tanturri, V. (1935). Mschr. Ohrenheilk. 69, 1358.

Wilks, S. (1857). Trans. path. Soc. Lond., 8, 88. 